\title{
Innovative Implementation of Social Determinants of Health in a New Concept Based \\ Curriculum
}

* Kim A. Decker, PhD, RN, CNS

Clinical Assistant Professor

Corresponding author

Indiana University School of Nursing, SY 409

Bloomington, IN 47405

kidecker@iu.edu

Telephone: 1(812) 855-1729 Fax: 1(812) 855-6986

Desiree Hensel, PhD, RN, PCNS-BC, CNE

Associate Professor

Indiana University School of Nursing, SY 400

Bloomington, IN, USA 47405

dehensel@iu.edu

Thomas M. Kuhn, MSN, RN, APN-BC, COHN -S, CCM

Lecturer

Indiana University School of Nursing, SY 405

Bloomington, IN, USA 47405

tmkuhn@iu.edu

Chad Priest, JD, MSN, RN

Adjunct Assistant Professor of Emergency Medicine

Indiana University School of Medicine

410 W. 10th St., Suite 3100

Indianapolis, IN 46202

cspriest@iu.edu

Adjunct Assistant Professor of Nursing

Indiana University School of Nursing

600 Barnhill Drive

Indianapolis, IN 46202

cspriest@iu.edu

Chief Executive Officer - Indiana Region

American Red Cross

Indianapolis, IN 46202

chad.priest@,redcross.org

The authors have no conflicts of interest to declare.

This is the author's manuscript of the article published in final edited form as:

Decker, K. A., Hensel, D., Kuhn, T. M., \& Priest, C. (2017). Innovative Implementation of Social Determinants of Health in a New Concept-based Curriculum. Nurse Educator, Publish Ahead of Print. 


\section{Acknowledgment}

The authors thank Dr. Joyce Splann Krothe for her guidance in developing the community health content in this new concept based curriculum.

Conceptual education is a prominent movement for the future of learning - not just in nursing, but in many other disciplines as well (1). It centers on the idea that concepts can be used for creating unified principles, or classifications, that organize learning while bolstering understanding (1). Many experts also have recommended that clinical education move beyond the hospital setting toward a broader variety of clinical experiences in the community setting (2). These recommendations coincide with the Institute of Medicine's (IOM) report that encourages the establishment of innovative educational approaches in various community settings (3). They are also congruent with the Essentials of Baccalaureate Nursing Education for Entry Level Community/Public Health Nursing Practice's recommendations for preparation of entry-level

community health/public health nurses $(4,5)$. The purpose of this teaching brief is to illustrate how nursing faculty incorporated concepts of social determinants of health, utilizing various community clinical experiences, throughout an undergraduate nursing program (6).

\section{Implementation and Outcomes}

As part of an undergraduate nursing program's curriculum revision, we piloted the use of a constructivist approach $(7,8)$ to develop community health coursework. Constructivism is based on the premise that students create new concepts or ideas centered upon their present and past knowledge $(7,8)$. This theoretical framework encourages learners to actively participate in their learning by observing, thinking, feeling, and conversing, as learning for understanding is the key to this process $(7,8)$. A primary goal for this new concept based curriculum was to prepare students for practice in the changing health care environment by integrating community 
health concepts throughout the curriculum, framed within the social determinants of health (6). The objective was to corroborate how social environment (i.e., psychosocial, behavioral, and material) can have a prevalent effect on physical aspects of health (6). Institutional Review Board approval of exempt research was obtained to study the students' course work ( $\mathrm{n}=60$ per class) for each class level in which the new concept based curriculum's community health courses were taught.

Our intent was to introduce community-based concepts at the beginning of the nursing curriculum in group learning activities. In the first undergraduate community course, students viewed the film Unnatural Causes, showcasing a major city's social determinants of health and health disparities within city districts (9). The film screening was followed by discussion. After this activity, the students participated in a poverty simulation, which utilized real-life vendors in the community. For example, the food bank vendor works in our local food bank; the banker vendor is an actual banker in our community; the policeman is both a graduate of our nursing program and an actual state trooper - he came to the simulation in his officer's uniform. From students' and volunteers' post-poverty simulation surveys, the use of "real people" as vendors made the experience richer. At the end of the simulation, each vendor talked about his or her role in the community and provided examples of what he or she does in encounters with people who are part of a vulnerable population. Using the short from of the Attitude Toward Poverty Scale (10), findings revealed that after the simulation students' understanding of poverty increased, although many students continued to believe that poverty was linked to individual behaviors (11). This scale is a reliable and comprehensive assessment of poverty-related attitudes in undergraduate students with an internal consistency extending from .87 to .89 and a factor analysis equal to or greater than $.40(10)$. 
During the semester, students were involved in the Culture of Care: Bystander Intervention Project, which was initially developed due to national health and safety concerns on university campuses. Tragic outcomes, which could have been stopped if bystanders had just acted, were happening nationally. The students were taught via lecture and discussion about bystander intervention techniques focusing on the 4 specific culture of care areas: sexual wellbeing, mental health, alcohol and drug awareness, and respect. Students were then asked to participate in 6 or more clinical hours in at least 1 of these focus areas within the campus community. Students engaged in a variety of activities to develop their skills as leaders, health promoters and professionals (12). These skills were measured by mapping individual activities with journal entries (12). Examples of these activities were monitoring safety during parties where drinking has taken place and disseminating information to others regarding the 4 topic areas (12). In each of these activities, the nursing students supported other students, either individually or in group settings (12).

Once a week, the nursing students also led an elementary after-school program called Goal University, using a previously developed lesson plan. Goal University is a community health based program focusing on obesity prevention in families and the schools. Review of surveys on the experience revealed that the nursing students helped elementary school students make positive changes in healthy eating knowledge and behaviors, such as eating breakfast more frequently.

For community health clinical experiences in the junior year, the nursing students, in groups of 2 to 4 , spent 20 hours in a higher risk clinical setting. They interacted directly with clients at a local homeless low-barrier day shelter. A certified family nurse practitioner faculty member was present with the students in this clinical setting to ensure safety of the students and 
also to assist with helping the students with clients' physical and emotional health care needs. Analysis of student journals and interviews with students following this clinical experience revealed positive changes in attitudes toward individuals experiencing poverty. This experience built on their foundational understanding of poverty to help them understand the unique problems of the homeless.

In the final year of the nursing program, the senior students spent their community clinical practicum at more autonomous and specialized community health sites. These students worked one-on-one with clients on their own, with individual preceptors guiding the nursing process. The clinical sites included the local center on aging, volunteers in medicine clinic, community health services, home health care, home hospice and hospice house, infection control, school nursing, wound and diabetes center, a weekend camp for adults with disabilities, urgent care, and occupational health settings. Didactic classes focused on social determinants of health. At the conclusion of the program, these students were asked to summarize how the constructivist approach to community health nursing helped them develop as a nurse $(7,8)$. Analysis of these student journals revealed that the students were able to process the key, overall aspects of social determinants of health. Many of the journal entries stressed the importance of exposure to these concepts throughout students' nursing training, as it prepared them for postgraduation.

\section{Results}

Throughout this new concept-based curriculum, total scale ratings of the Attitude Toward Poverty Scale (10) increased with each exposure to poverty $(\mathrm{T} 1=65.6, \mathrm{~T} 2=75.5, \mathrm{~T} 3=76.8)$, suggesting that the tiered constructivist approach helped in promoting caring, nonjudgmental attitudes towards those living in poverty among students. Review of the students' community 
health journals suggested that they felt empowered to decrease their clients' health risks as their own level of autonomy and responsibility increased in various clinical settings. Scheduling and making clinical guidelines clear enough for beginning students to practice in more autonomous settings presented significant challenges. Finding meaningful clinical sites is also challenging and a continual process.

\section{Conclusion}

Increasing levels of complexity in the community health setting helped students gain a wide-ranging view of the nurse's role beyond the acute care setting. While only focusing on one prelicensure nursing program, this synopsis serves as a guide for other nursing institutions integrating social determinants of health and community health concepts throughout their curricula. 


\section{References}

1. Giddens, JF. Concepts for nursing practice. St. Louis, MO: Mosby/Elsevier: 2013.

2. Benner P, Sutphen M, Leonard V, Day L. Educating nurses: A call for radical transformation. San Francisco, CA: Jossey-Bass; 2010.

3. IOM (Institute of Medicine). The future of nursing: Leading change, advancing health. Washington, DC: The National Academies Press; 2011.

4. Callen B, Block D, Joyce B, Lutz J, Schott NB, Smith CM. Essentials of baccalaureate nursing education for entry level community/public health nursing. Association of Community Health Nursing Educators (ACHNE). http://achne.org/i4a/pages/index.cfm?pageid=1. Published Fall, 2009. Accessed March $30,2016$.

5. Swider SM, Krothe J, Reyes D, Cravetz M. The quad council practice competencies for public health nursing. Public Health Nurs. 2013;30(6):519-536.

6. Marmot MG, Wilkerson RG. Social determinants of health. (2 ${ }^{\text {nd }}$ ed.). New York, NY: Oxford University Press, Inc.; 2006.

7. Bruner J. The process of education. Cambridge, MA: Harvard University Press; 1960.

8. Bruner J. The culture of education. Cambridge, MA: Harvard University Press; 1996.

9. Adelman L, Smith L. Unnatural causes...is inequality making us sick [DVD]. United States: California Newsreel; 2008.

10. Yun S, Weaver R. Development and validation of a short term of the attitude 
toward poverty scale. Adv Soc Work. 2010:11(2):178-187.

11. Work J, Hensel D, Decker KA. Q methodology study of perceptions of poverty among Midwestern nursing students. Nurse Educ Today. 2015;35(2):328-332.

12. Decker K, Hensel D, Fasone L. Outcomes of a bystander intervention community health service learning project. Nurse Educ. 2016;41(3):147-150. 
